\title{
Imaging of pheochromocytoma and paraganglioma: moving beyond "lumpology" with SSTR, FDG and MIBG molecular imaging
}

\author{
MS Hofman*, D Pattison, RJ Hicks \\ From International Cancer Imaging Society Meeting and 15th Annual Teaching Course (ICIS 2015) \\ London, UK. 5-7 October 2015
}

\section{Learning objectives}

Cancer staging traditionally uses CT or MRI for detecting suspected malignant lesions with characterisation performed by histopathology following biopsy. In this "lumpology" paradigm, the number, size and location of lesions are used to determine prognosis and guide treatment strategies. To provide an educational exhibit to highlight the utility of molecular imaging to diagnose, stage and characterise pheochromocytoma (PCC) and paragangliomas (PGL) phenotype and guide patient management.

\section{Content organisation}

Pictorial review of ${ }^{68} \mathrm{Ga}$-DOTATATE (GaTate), ${ }^{18} \mathrm{~F}$ fluorodeoxyglucose (FDG) and ${ }^{123} /{ }^{124}$ I-metaiodobenzylguanidine (MIBG) imaging. Within the "lumpology" paradigm, molecular imaging performs well with a superior sensitivity and specificity compared to CT or MRI. The real strength of molecular imaging, however, is in characterizing different PCC/PGL phenotypes which can assist in identifying the underlying type of PCC/PGL with consequent management impact including selection of patients for radionuclide therapy. PCC/PGL can be broadly divided into a pseudohypoxic cluster and tumours mutations of receptor tyrosine kinase signalling. Mutations in the pseudohypoxic cluster lead to inhibition of oxidative phosphorylation and activation of glycolytic pathway via the Warburg effect leading to high sensitivity of FDG. Owing to high somatostatin receptor expression across the range of $\mathrm{PCC} / \mathrm{PGL}, \mathrm{GaTate} \mathrm{PET} / \mathrm{CT}$ is emerging as the single most useful modality. Positivity of MIBG is variable paralleling the varied catecholamine

\footnotetext{
* Correspondence: michael.hofman@petermac.org Centre for Molecular Imaging and Neuroendocrine Tumour Service, Peter MacCallum Cancer Centre, Melbourne, Australia and Department of Medicine, University of Melbourne, Australia
}

secretion profile of PCC/PGL. Knowledge of other patterns such as activation of brown fat on FDG or suppression of physiologic adrenal activity on GaTateare important in interpretation.

\section{Conclusion}

Molecular imaging is valuable in diagnosing, staging, restaging and characterizing PCC/PGL. Integration of the molecular imaging phenotype into patient management is complementary to genetic testing and histopathology, and critical to the true realization of personalised medicine.

Published: 2 October 2015

doi:10.1186/1470-7330-15-S1-P49

Cite this article as: Hofman et al:: Imaging of pheochromocytoma and paraganglioma: moving beyond "lumpology" with SSTR, FDG and MIBG molecular imaging. Cancer Imaging 2015 15(Suppl 1):P49.

Submit your next manuscript to BioMed Central and take full advantage of:

- Convenient online submission

- Thorough peer review

- No space constraints or color figure charges

- Immediate publication on acceptance

- Inclusion in PubMed, CAS, Scopus and Google Scholar

- Research which is freely available for redistribution

Submit your manuscript at www.biomedcentral.com/submit
() Biomed Central 